\title{
Essential Factor Analysis to the Site Selection for the Administration Center of the Minority Area
}

\author{
Mingshu Li \\ School of Architecture and Urban Planning \\ Huazhong University of Science and Technology \\ 1037 Luoyu Road, Wuhan 430074, China \\ Tel: 86-27-6274-4746Ｅ-mail: tonny168@126.com \\ Mindong $\mathrm{Ni}$ \\ School of Architecture and Urban Planning \\ Huazhong University of Science and Technology \\ 1037 Luoyu Road, Wuhan 430074, China
}

\begin{abstract}
China's minority area is vast in territory and fruitful in resources. The minority area occupies considerable proportion of China, but its local economy and urban construction was relatively backwardness. Along with the unceasing development of the economy and urbanization, the town construction in this area is speeding up day by day. As an important component of the city, the administrative center's site selection is getting increasingly important. The author unifies the experience of the site selection for the administration center in the multi-national area, figures out some essential factors of the site selection, and carries on the simple analysis to the essential factors.
\end{abstract}

Keywords: Minority area, Administration center, Site selection, Essential factor, Analysis

\section{Introduction}

China's minority area is vast in territory and fruitful in resources. Up to 1997, the autonomous areas amounted to 6,162,900 square kilometers, accounted for 64.2\% of the nation's total area. (Jia Donghai, 2007 See also Figure 1). Along with the unceasing development of the economy and urbanization, the town construction in this area is speeding up day by day. As an important component of the city, the administrative center's site selection is getting increasingly important. The author unifies the experience of the site selection for the administration center in the multi-national area, figures out some essential factors of the site selection, and carries on the simple analysis to the essential factors.

\section{Insert Figure 1 Here}

\section{The positive impacts of administrative center relocation on city's development}

\subsection{Guides the urban development}

The social economy development and the speed up of the urbanization not only provide the opportunity for the city's development, but also set the new request to the urban function and the spatial structure, so the urban function layout often needs a significant adjustment. The administrative center is the hub of the city's administrative institutions, its site selection and the construction manifest the government's policy support and capital input to the local development, therefore may lead the fast development in the new urban areas.

\subsection{Reduce the pressure of old urban areas}

In many Chinese cities, the city's constructions often take the old city as the center and expand on the circle level type. The public activity centers still gather in the old city, which lead the population density to be excessively high, the infrastructure load to be heavy and the public service facilities to be insufficient. If the city continues taking the old city as the center to develop, will inevitably causes the large-scale old city renovation, which will not only increase the 
economic cost, but also destroy the historical layout. The administrative center's relocation may improve the work condition and provides the space for old city's other functions, it may also help to protect the heritage attractions and the traditional style.

However, if the location of administrative center is selected improperly and cannot be coordinated with the region development opportunity and the urban economy strength, it will be very difficult to lead the development in the new urban areas, it will also increase government's financial burden and bring the negative influence for the urban development.

\section{The essential factors}

\subsection{Cultural of minority nationalities}

In the process of the long-term development, various nationalities create their own culture, including the material culture and spiritual culture, with the national characteristics to reflect the national history and social life.

Fully consider and respect the national culture in the area in the site selection process, and integrate the national culture to the architectural feature of the administrative center.

\subsection{Scale and function of the administrative center}

In China, an urban Administration Centre is the place for the Party and government organizations to exercise urban political decision-making. Our country generally calls all levels of Party committees and government posts as "administration centres". The Urban Administration Centre, refers in particular to municipal state agencies, which generally include the Four Big Organized Groups: The Municipal Party Committee, City National People's Congress, The Municipal Government and The City Political Consultative Conference. The Urban Administration Centre includes the constructions and their extended construction area.

Based on the analogy analysis of the domestic cities' relative material and the predict of the urban forward population, we can calculate the land and building scale of the administration center.

\subsection{The development direction according to the city's Master Plan}

The location of the urban administration center has the major impacts on the urban economic development, the layout structure, the road system plan and the organization of architectural esthetics space. So the location selected should be more forward-looking, and the centre should be timingly distributed in the city's future prioritized region to come in line with the city's master plan. This is because, in the citizens' opinion, the government is the confidence guarantee, a commercial building possibly goes bankrupt, but the administration building relatively is much safer. Only under the government's construction, the infrastructure (water, electricity, road, gas etc.) and servicing facilities (hospital, school, posts and telecommunications, public security etc.) can form the high level in a short period in the newly developed area, this is what the developer would be unable to achieve.

\subsection{Driving the development in the new urban area}

In the market economy, the city is the result of the country's long-term and large amount funding investment, is the capital physical form, and is also the greatest visible state asset belongs to the government. The government is able to utilize the market economy as a method to gather, reorganize and operate the natural growth capital (land, for example), manpower function capital (road, bridge, for example) and related extending capital (name the roads and bridges, for example). So the government can stimulate the storage to the greatest advantage, can take a new road of "building city with city" and "revitalizeing city with city, and can also realizes the urban self-accumulation and the self-increment.

Along with the implementation of the land's paid use and the market economy development, the price variance of the different location's land is obvious day by day, this requests that the "goldener" the land is the more outputs it should produce, and "the highest rent principle" is asked to be followed which means that lands should be occupied by the high-output professions such as finance or insurance.

Because of the lead role of the center's development to the city socio-economic development, its site selection should fully consider the sustainable development of its peripheral space which means its peripheral space must have the sufficient land for development and construction. Only in this way, the center can fully display its social economy benefit and become the city's point of growth.

According to The Central Place Theory, in the isotropic region, the zone with the strongest power of the gathering, radiating and exemplifying is located generally at the central place of the future prioritized region. Therefore, in the process of relocation, the center generally should be located at the prioritized new area, in order to causes it to become the point of growth of the urban space and the socio-economic development. 


\subsection{Site's natural conditions}

The administrative center is a important architectural complex and urban space, so it should be built on a land with more superior physical geography condition. For example, the location should consider the geology topographical condition to avoid the disaster risk, and should not be on the land with excessively low topography to avoid the flood disaster. The suitable location should has sufficient space to use, and its slope and elevation difference is gentle, the bearing capacity of soil foundation is strong and its draining system is quite good in the region.

The traditional Feng-Shui theory named the site selection for the public activity center as "The Acupoint Selection", the administrative center is the Central Acupoint (is also called "Hall Acupoint”), and should be prioritizely located in the south of mountain and the north of water with high topography. In this traditional Feng-Shui pattern of backing-mountain and facing-water, it is highly advantageous to form a good ecological and partial microclimate, is a model of valuable land with a good Feng-Shui (Gao Shiming, 2006).

\subsection{Traffic conditions}

A cardinal principle of the site selection is to establish the centre in a well communicational area. As an urban administration center, on the one hand, it should provide the service very conveniently for the residents, on the other hand, it must avoid forming the traffic bottleneck in the local area. The centre is a place to be visited by the public, therefore it should be located beside the main city roads (or not far from the main roads), but should avoid the cross-boundary roads. It also should be close to the life main road and the mixing main road, but should not very close to the transportation main road.

\subsection{Development cost and feasibility}

The center's construction is quite a huge project, therefore, the principle of the feasibility should be insistly considered by all means in the process of the site selection and its construction. The planning department should carry on thorough inspection and proof on the base condition, relocation situation and the economic efficiency of the prospective locations, then choice the relatively investment-saving and developmet-driving proposal. In this way, the construction of the administrative center might be of good operationality. The quantity of the buildings would be removed and the terrain slope of the land are the two important attributes affect the construction cost (Chen Xiugang, 2003).

\subsection{Favorable to mold the urban landscape characteristic}

The administrative center is the city's living room, the city's landmark construction, and the window displaying the city's image, therefore, the site selection of administration center in the multi-national area should fully consider the national landscape characteristic with the physical geography condition, the centre should be located in the place with symbolize significance where is in the superior geography condition and easy to create a national landscape characteristic.

\section{Conclusion}

The economy and urban construction in the minority area is relatively backward, if through the urban administration center's relocation, the city can promote the urban image, improve the urban appearance, and stimulate the urban economy development, then the city can proceed to lead the sustainable and unceasing economy development in the multi-national area, the site selection for the urban administrative center is truly successful.

\section{References}

Chen, Xiugang. (2003). Discussion on the principles of the site selection for the urban administration center. Journal of Planners, (5): 80-82.

Gao, Shiming, Wang, Liang, Wang, Mingtian \& Liu, Yingquan. (2006). The site selection for the urban administration center based on urban renewal---Take the Sanshui District of Foshan City as example. Journal of Planners, (5): 45-48.

Jia, Donghai. (2007). On the innovation and political civilization of regional autonomy for nationalities. Journal of Southwest University for Nationalities (Humanities and Social Science), (7): 16-19. 


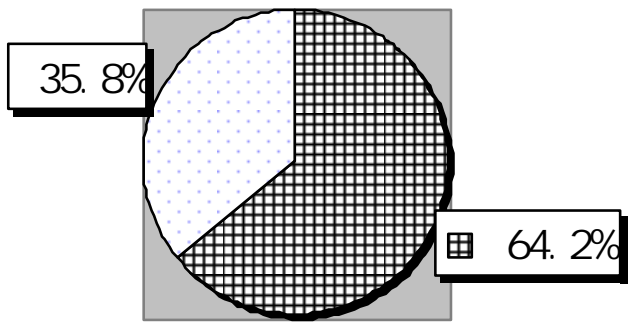

囲 mi nor i ty area $\square$ Non- mi nor i ty ar eas

Figure 1 . The proportion of the minority area accounts for the national area 